\title{
On the Limits of "Gaie" Spaces: Discursive Constructions of Women's Sport in Quebec
}

\author{
Barbara Ravel \\ Université de Montréal
}

\author{
Geneviéve Rail \\ University of Ottawa
}

Several studies on the experiences of nonheterosexual women in sport have highlighted the development of lesbian subcultures in sport, while others have emphasized the scarcity of athletic contexts embracing sexual diversity. This article explores the narratives of 14 young Francophone sportswomen positioning themselves as "gaie," lesbian, bisexual, or refusing labels altogether. Using a feminist poststructuralist perspective, we examine their discursive constructions of sport and argue that the discourses articulated in sport allow for the creation of a space of resistance to heteronormativity. We suggest that the sport space is constructed as a "gaie" space within which a normalizing version of lesbian sexuality is proposed. We investigate how in/ex/clusion discourses are inscribed in space and how subjects are impacted by and, in turn, impact these discourses.

Plusieurs études sur les expériences des femmes non-hétérosexuelles en sport ont souligné le développement des sous-cultures lesbiennes en sport, alors que d'autres ont mis l'accent sur la rareté des contextes sportifs embrassant la diversité sexuelle. Cet article explore les récits de 14 jeunes sportives francophones s'identifiant en tant que gaies, lesbiennes, bisexuelles ou refusant toute étiquette. A partir d'une perspective poststructuraliste féministe, nous examinons leurs constructions discursives du sport et suggérons que les discours circulés dans ce sport permettent la création d'un espace de résistance à l'hétéronormativité. Nous suggérons également que l'espace sportif est construit en tant qu'entité « gaie » au sein de laquelle une version normalisée de la sexualité lesbienne est proposée. Enfin, nous investiguons comment les discours d'inclusion et d'exclusion sont inscrits dans cet espace, comment ils influent sur les sujets et comment les sujets, à leur tour, influent sur ces discours.

Since mid 2005, same-sex couples have been allowed to marry in Canada. This situation places Canada alongside the Netherlands and Belgium as human rights leaders worldwide. Before the legalization of marriage between same-sex couples

Ravel is with the Department de Kinesiology, Université de Montréal, C.P. 6128, succursale Centre-Ville, Montréal Québec; Rail is with the School of Human Kinetics, University of Ottawa, Ottawa, Ontario. 
at the federal level, several provinces had already legalized "gay marriage." One of these provinces was Quebec, which is a province that not only possesses a very distinct culture but is also one of the most open toward diversity in Canada, and, arguably, worldwide. It is certainly not by chance that the 1 st World Outgames, ${ }^{1}$ which took place in the summer of 2006, were held in Montreal, Quebec's largest city. Although conceived as an international event open to everyone, the Outgames especially rallied the lesbian, gay, bisexual and trans (LGBT) community around athletic and cultural competitions and thereby offered the community an opportunity to gather in the largest Francophone metropolis in North America.

Recently, several studies have focused on the experience of gay and lesbian athletes in sports organized for LGBT populations (e.g., Jarvis, 2006; van Ingen, 2004) and in traditional sports (e.g., Fusco, 1998; Le Blanc, 2002). Echoing contemporary studies of gender and sexuality, a certain number of sport sociology researchers have started to investigate these issues in light of poststructuralism and queer theory (e.g., Broad, 2001; Caudwell, 1999, 2003, 2006; Cox \& Thompson, 2000; Eng, 2006). Whereas initial studies of gays and lesbians in sport were based on the assumption that gender and sexuality were fixed constructs, more recent studies tend to borrow from poststructuralist and queer theories (e.g., Butler, 1990; de Lauretis, 1993) to examine the experiences of athletes whose sexuality is no longer expressed in terms of hegemonic categories but is rather seen as fluid and changing. These studies often emphasize the presence of heteronormative discourses in sport and occasionally report the existence of alternative discourses on gender and sexuality (e.g., Broad, 2001; Eng, 2002). In line with these more recent studies, we are interested in using a similar theoretical framework to examine how sport in a city such as Montreal is experienced by women with non-conventional sexualities. Considering this specific socio-cultural context, we ask the following question: How do women with non-conventional sexualities discursively construct their sport space? As a subquestion, we also ask: How are these women's constructions of sport experiences impacted by the discourses circulated within their sport space, as well as within the larger society in which they live?

\section{Sport, Sexuality, and Spatiality}

Literature on lesbians in sport has shown mainstream sport to be unwelcoming to non-heterosexual women because of pervading homophobia, heterosexism, and homonegativism² (e.g., Cahn, 1993, 1994; Fusco, 1998; Griffin, 1992). Other researchers of women's sport have identified the consequences of homophobia, heterosexism and homonegativism, as well as athletes' strategies to reduce their impact (Fusco, 1998; Griffin, 1992, 1998; Krane, 1996). Non-heterosexual athletes have been found to express non-conventional sexuality in different ways and, despite the fact that such ways may imply varying degrees of disclosure of their sexuality, many seem to counter homophobia and heterosexism (Fusco, 1998). Whereas Fusco (1998) and Griffin (1998) have suggested that being out implies coming out first, Iannotta and Kane have argued that alternative strategies of coming out and being out exist (2002). More specifically, these authors have emphasized the existence of "nonlinguistic actions" (p. 366) as ways of expressing one's sexuality and have highlighted their positive impact on reducing homophobia. While the more covert 
strategies of being out seem beneficial at the team level, we could argue here that they may also, simultaneously and paradoxically, perpetuate silence and reproduce status quo within sport and society more generally.

Although many studies have reported that it is difficult to be a lesbian in sport, some have also drawn attention to the fact that many athletes are nevertheless out and tend to gather. A number of authors have shown the existence of lesbian sub-cultures in sport (e.g., Mennesson \& Clement, 2003; Riemer, 1997), which may become a refuge for non-heterosexual players (Cahn, 1993; Hekma, 1998). For example, studies of softball in the U.S.A. have emphasized the development of lesbian subcultures that serve as an alternative to bars and provide access to the LGBT community (Cahn, 1993, 1994; Riemer, 1997). Shire, Brackenridge and Fuller (2000) have examined the composition of a varsity field hockey team in the United Kingdom over a 10-year period in terms of "heterosexual" versus "lesbian" players. These authors have described changes in the ratio that attested to a mainly non-heterosexual team in the last years and that allowed rather homophobic discourses to be replaced by ones that were positive towards non-conventional sexualities. Moreover, they have suggested that the team developed contacts with some of the city's LGBT bars as a result of the closing of a campus bar where the players gathered regularly.

Some of these researchers seem to draw on an essentialist conception of sexuality. Such a conception reinforces the heterosexual/homosexual binary and suggests that sexuality cannot be constructed outside hegemonic categories. Several scholars have challenged the assumption that sexuality is a fixed construct and suggested that it is discontinuous, changing and fluid (Butler, 1990; de Lauretis, 1993). Similarly, several authors have relied upon "post" theories in designing their study on women's sport and sexuality (e.g., Broad, 2001; Caudwell, 1999, 2003, 2006; Cox \& Thompson, 2000; Eng, 2006). Notably, feminist poststructuralism has been favoured to investigate sport and, more specifically, to examine how knowledge is produced in ways that serve to maintain gendered power relations. Feminist poststructuralism can be usefully understood as both a method and a theoretical reflection to understand existing power relations and identify areas for change. Resisting the notions of absolute truth and objectivity, it suggests that knowledge is changing as it is discursively constructed through language (Gavey, 1989; Weedon, 1997). While not fixed, this knowledge still has an effect. Following Foucault (1972, 1973, 1977), poststructuralism posits that knowledge defines subjects and that discourses refer not only to the meaning of language but also to the real effects of language use. Discourses are "regimes of truth" (Foucault, 1973) and, as such, they specify what can be said or done at particular times and places, they sustain specific relations of power, and they construct particular practices (Rail \& Harvey, 1995). Poststructuralism acknowledges the crucial roles of language and discourse in the constitution of an individual's subjectivity. Poststructuralism suggests that subjectivity is constituted within social discourses and cultural practices, thus it is changing, fragmented and often discontinuous. According to Weedon (1997), subjectivity can be described as "the conscious and unconscious thoughts and emotions of the individual, her sense of herself and her ways of understanding her relation to the world" (p. 32). Although limited, agency still has meaning within poststructuralism as subjects position themselves along complex (and sometimes 
contradictory) discourses and negotiate this position within social practices that are inscribed in the visual as well as the spatial (Foucault, 1977; Weedon, 1997).

Itself greatly influenced by poststructuralism (Epstein, 1996; Weedon, 1999), queer theory questions the traditional relation between sex, gender and sexuality, and suggests that these constructs must be seen as fluid (Butler, 1990; de Lauretis, 1993). By destabilizing the binary categories of sex, gender and sexuality, queer theory — and Butler's, in particular, as found in Gender Trouble (1990)—questions the "naturalness" of these categories. In this respect, queer theory stresses the notion of "performativity" in that sex, gender and sexuality are not stable or "natural," rather they are the results of a repeated performance of a given sex, gender or sexuality. It is through performative acts that sex, gender and sexuality appear "normal" and create an illusion of reality (Butler, 1990, 1993). In Butler's terms, we must think of performativity "not as a singular or deliberate 'act', but, rather, as reiterative and citational practice by which discourse produces the effects that it names" (1993, p. 2). Butler's theory and project are definitely queer, then, as they underline the artificial and performative nature of sex, gender and sexuality identities. By critiquing the assumptions of hegemonic heterosexuality and exposing the heterosexual matrix, Butler subversively challenges the status quo and advances the cause of marginalized identities.

Poststructuralism and queer theories have been incorporated in a number of sport studies so far. Broad (2001), for example, has argued that women's rugby in the U.S.A. offers a safe and welcoming environment for non-heterosexual athletes and has suggested the progressive potential of rugby. Indeed, she has argued that "rugby players challenge heteronormativity through gendered transgressions and gendered disruptions of the homosexual/heterosexual binary" (p. 195) and consequently suggested the existence of a "queer resistance" in women's rugby. Resistance to heteronormativity has also been emphasized in studies in which authors have tried to deconstruct the multiple discourses on gender and sexuality in women's sport and physical education (Caudwell, 1999; Cox \& Thompson, 2000; Sykes, 1998; Veri, 1999). For instance, Cox and Thompson (2000) have examined the experiences of female soccer players in New Zealand and the varied discourses with which they constructed themselves as soccer players, women, and heterosexual/non-heterosexual individuals. In another study, Sykes (1998) has used the figure of the closet in Canadian women's physical education to highlight the dynamic process in which complementary discourses concur to simultaneously normalize heterosexuality and silence lesbian sexuality.

Researchers in sociology (e.g., Duncan, 1996; Grosz, 1995) and sport sociology (e.g., Fusco, 2006a; Vertinsky, 2004) have used a similar theoretical framework and proposed to investigate the sport space in that it is actively de/re/constructed by both subjects and discourses. "Space" is often understood in its Lefebvrean sense and seen as fluid, constructed, and constantly altered (Lefebvre, 1991; Soja, 1989). As suggested by van Ingen (2004), "all spatial locations are dialectically constructed through social interactions and are saturated with relations of power" (p. 254). Spatial ethnography can thus be considered as complementary to feminist poststructuralism, as it seeks to bring to light how competing discourses and power relations are inscribed in space (Cresswell, 1996; Keith \& Pile, 1993; McDowell, 1999), as well as how potential for resistance can be found within space. To this 
end, it is interesting to ask "how" subjectivity is discursively constituted in social space and "how" space is discursively constructed as gendered and sexualized since gender and sexuality have been found critical to the construction of space (Bell \& Valentine, 1995; Duncan, 1996; Valentine, 1996).

Recent studies by Caudwell (2007), Fusco (2005, 2006a, 2006b), Muller (2007) and van Ingen $(2003,2004)$ are of particular interest in this regard. Fusco (2005) has used a spatial ethnographic perspective to highlight how multiple discourses intersect with sport, race and subjectivity in the space of a locker room. She has highlighted how the locker room is racialized and constructed as a "white(ned)" space reinforcing White hegemony. By drawing on Western ideas about hygiene and purity, she argues that the locker room actually tends to not only marginalize non-white bodies but also non-heterosexual and more generally non-normative (e.g., unfit, aged) bodies. Discourses that emphasize the "respectability" of the locker room are rarely resisted since this space seems rarely disrupted. As Fusco put it, "the powerful discourses and meta-narratives of modernity that govern white(ned) space-respectability, degeneracy, renewal, progress, regeneration, and discourses of aesthetic modernism-constrain, more than enable, resistance in this space" (p. 303).

Drawing on Lefebvre's work (1991), van Ingen (2004) has argued that power relations are crucial to the understanding of a LGBT running club as a "social space" (2004). She has emphasized the processes responsible for the spatial exclusion of certain social identities, notably by bringing to light the absence of unhealthy, nonwhite and non-gay bodies in the running club. For instance, the author has revealed how the running club is constructed as a space reproducing social hierarchies and hegemonic powers in that it positions whiteness as the "norm" and systematically erases non-white minorities. As van Ingen has pointed out, this significant feature of the running club appears to be in stark contrast to the city's acknowledged racial diversity: "The apparent unremarkability of Whiteness works to hide the ways in which racialized power relations deeply shape encounters and sustain existing special arrangements in landscapes of social relations" (2004, p. 264).

Similarly, Muller (2007) has examined WNBA (Women's National Basketball Association) spaces through two case studies (e.g, a kiss-in protest organized by lesbian fans during a game in New York and the experiences of lesbian fans from Minnesota). She has shown how the lesbian presence tends to be erased from the WNBA spaces while heteronormativity "is naturalized, as well as accepted and resisted by lesbian fans in both New York and Minnesota" (p. 197). Muller has illustrated how marketing strategies of the Minnesota WNBA team revealed the ambiguity of WNBA spaces through the simultaneous promotion of the "heterosexual" image and the implicit acknowledgement of the lesbian presence among the fans. Moreover, through the examination of the dynamics of the kiss-in protest, the author has revealed the contradictions underlying such an event. The Lesbians for Liberty who organized the kiss-in attempted to counter the heterosexual hegemony of WNBA spaces and seek attention to the lesbian presence within these spaces. Yet, the strategy failed notably because competing discourses circulated among lesbian fans and prevented them from uniting in this "act of resistance" (p. 204). Muller has concluded that the event challenged the idea of a cohesive and unified lesbian identity and instead revealed the complexity of lesbian identities. 
In her study of a lesbian-identified soccer team in England, Caudwell (2007) has also explored the issue of space and the diversity of sex-gender-sexuality experiences, notably by focusing on "marginalized" players: the femme-inine player/defender and the transsexual player/striker. Caudwell has argued that in this "out" lesbian team space, the butch embodies the authentic lesbian gender and constitutes the perfect defender. In this manner the presence of a femme lesbian player at this position challenges the butch dominance within the soccer space while also disturbing the normativity of the order woman-masculine-lesbian. Caudwell has also examined the multiple discourses that are (re)produced by some of the players in reaction to the presence of a transsexual player in another lesbianidentified team. She has found that the transsexual player's ability to score goals was situated within essentialist discourses about sex that assume that being born as a man gives her an "unfair advantage" (p. 192) on the soccer field. Caudwell has observed that even in such explicitly lesbian team spaces, "some players are unable to think beyond dominant sporting discourses that promote the notion of a natural sexed body as well as the idea of sex differentiation as the core of competitive participation" (p. 192).

The complex experiences of women with non-conventional sexualities therefore seem to require an approach inspired by poststructuralism and queer theory. There is however, a need for further knowledge with regards to how non-heterosexual women express their sexuality in sport spaces. On the basis of our review of the literature we conclude that most studies have been conducted in communities that were not particularly tolerant of a diversity of sexualities. Furthermore, studies have mostly focused on English-speaking women so that little is known about the sport spaces of women with non-conventional sexualities belonging to other linguistic cultures. The present study thus addresses a number of questions so far unanswered: How do Francophone women with non-conventional sexualities living in Montreal construct their sport space? How do they perform sexuality within this space? How do their narratives echo dominant or alternative discourses on gender and sexuality circulating in Montreal and in Canadian society in general? To answer these questions, we have attended to a number of methodological considerations.

\section{Methodological Considerations}

Feminist poststructuralism and discourse analysis have shaped our study. We collected narratives by conversing with the participants. We attempted to minimize power relations between the researcher and the participants by emphasizing the value of the participants' experiences (Fontana, 2002; Jansen \& Davis, 1998; Kvale, 1996). The first author, a 28 year-old queer female ice hockey player, engaged in the conversations which allowed for a climate of mutual understanding that favored exchange and reciprocity. Though facilitated by a conversation guide that covered a large range of topics, the interactions with the participants took the form of "real" conversations where two persons shared their experiences as non-heterosexual women in sport.

Conversations took place in Montreal from the fall of 2004 to the spring of 2005, following approval for the study by the Université de Montréal Ethics Committee. Participants were recruited through the snowball method. A total of 
14 white Francophone women were involved in the study. ${ }^{3}$ It is worth noting that these women often participated in two sports and that most played in mainstream (or supposedly but not entirely "straight") leagues, while a few played in LGBT leagues. At the time of the study, these women were between 21 and 31 years of age and lived in Montreal mainly as post-secondary students with part-time jobs or as women already engaged in diverse careers, mostly in the service industry. The audiotaped conversations were transcribed to yield "narratives" within which self-chosen pseudonyms were used to ensure the participants' anonymity (these pseudonyms are employed throughout the present paper). Narratives were returned in written form to the participants for verification. At this stage of data collection, we asked the participants to carefully examine the written materials and to elaborate upon or delete any part from the initial text.

The subsequent analytical process consisted of two consecutive methods of analysis. First, a thematic analysis took place. The Nud*ist Vivo qualitative data analysis software was used to help organize the text and regroup fragments of narratives into themes elaborated on the basis of their semantic affinity. Following this "vertical analysis" for each participant, we looked transversally or comparatively between participants. Transversal analysis allowed for a better understanding of the articulation of identity categories with constructions and experiences of sport and sport space. Second, a discourse analysis method informed by feminist poststructuralist theory (Denzin, 1994; Lupton, 1992; Minh-Ha, 1989; Rail, 1998; Weedon, 1997; Wright, 1995) was used to further explore the narratives. This analysis consisted in interrogating the narratives to document how our participants positioned themselves as "subjects" (Butler 1990, 1997) within the sport space and within dominant or resistant discourses of gender and sexuality. Moreover, this analysis helped us locate the "truths" that shaped our participants' constructions of their social realm. The focus of our discourse analysis was on how they constructed sport and sport space, on the role gender and sexuality discourses played in such constructions, and on the ways in which young women's meanings about sport were constructed in specific socio-cultural circumstances. We paid particularly attention to how the participants' subjectivity was constituted in space. To this end, our task consisted in bringing to light, through the participants' narratives, the power relations inscribed in the sport space as well as the potential for resistance in this space. Finally, following the analyses and interpretations, we offered the participants a fictional story presenting the most important findings and requested their feedback regarding the fictional story's resemblance to their own experiences. This strategy provided us with an additional opportunity to re-engage the participants in the research process and to verify the trustworthiness of our results. ${ }^{4}$

\section{Women's Sport as a Space of Resistance to Heterosexism}

While a majority of participants played in mainstream leagues (four participants played in LGBT leagues), all but two ${ }^{5}$ reported that they were "out" to their team. Indeed, the participants' narratives attested to the "lightness" of being out in sport regardless of the type of league (mainstream or LGBT). Their sport was mostly constructed as a space where it was not only possible and safe to be out 
but also sometimes where being non-heterosexual was an implicit norm, even in mainstream leagues. This is well exemplified by the following excerpt from the conversation with Marina ${ }^{6}$ a 24-year old ball hockey player:

We started to play in September. We had our suspicions about some of the girls but we didn't think that everybody was gaie. We went for dinner after the last game in December. We ordered drinks and, at some point, one girl said, "ok, let's go around the table and see who's gaie?" And it was "I am," "I am," "I am..." Everybody was gaie and we were floored. We couldn't believe that we were all gaie. It was very funny. Well, I have to admit that we were pretty naive to not think that that would be the case for most of us.

Echoing most of the participants' narratives, Marina's discursive construction of her ball hockey team and sport revealed a space constructed through discourses suggesting resistance to heterosexism. For most participants, it was recognized and accepted (although, in the above example, not explicitly stated) that many individuals are "gaie." This latter term may be understood in the context of the participants' self-identification with various sexual identities including bisexual, gaie, lesbian, queer, as well as sexualities not attached to any labels. Most participants tended to identify as gaie, a Francophone ${ }^{7}$ term that is quite popular in Quebec and that is usually considered the (linguistically) feminine form of " $\mathrm{gai}$ " - the latter being the Francophone translation of "gay." The term gaie often replaces the term "lesbian" although its usage shows some disassociation from this latter term-a paradox we shall examine in more detail in the following section.

Since most participants self-identified as gaie, it is not surprising to see that they discursively constructed their sport space as gaie notably by emphasizing the presence of women with non-conventional sexualities in their teams. Surprisingly, most participants were involved in mainstream leagues and a few reported having a majority of heterosexual teammates. In general, then, the participants' discursive constructions highlighted the openness of their sport space toward diversity and the so-called "normalness" of gaie sexuality within it. As a result, we argue that the participants' narratives challenged the traditional conception of space as "heterosexualised" (e.g., Duncan, 1996; Valentine 1996). Simone provides a statement that is quite representative, in this regard:

Slowly we became closer and, I don't know, I must have told everyone, one by one, on the team. Then, since everybody knew, we were out and open about it. It was no longer an unspoken fact; it was out in the open so we'd come to team practices and we'd exchange stories. It was like "what about your girlfriend?" . . In fact, I think that it showed the whole team that it was completely normal, that it's part of everyday life, that's all, and that the others don't have much to say about it. Actually, they realized that we were just normal girls, that it's just a part of us. (Simone, 29, handball)

The above passage reveals how alternative discourses about sexuality are available to create a sport space within which sexual diversity is "normalized" and sometimes celebrated, even in a context of heterosexual majority as in the previous example. It is noteworthy that several mainstream league participants discursively constructed their sport space in a way similar to LGBT league participants: a space 
in which heteronormativity was challenged and in which it was easy to be out as a woman with a non-conventional sexuality. Participants in LGBT leagues, however, rearticulated the idea that LGBT sport was specifically created and developed to provide a safe space for LGBT athletes by making possible moments of resistance to heterocentrism, heterosexism and homophobia. For some, such moments of resistance were realized by the simple involvement within a LGBT league while for others, it was the type of involvement that reflected an active resistance to heteronormalcy. In the following statement, Shane, a 23 year-old softball player, alludes to both:

Well, it's like, I just try to simplify every aspect of my life. For example, I just wanna play baseball, I don't wanna tell my life story to everyone I meet. So when I play in a gaie league, it's understood that I'm a lesbian and I don't need to explain my whole life to everyone, because everyone probably had a similar experience. So I can just concentrate on my sport, my hobby, and I don't have to explain it to anyone because everyone's gaie and so everyone understands. ... It was really great because you didn't have to justify anything; I mean, after the games, couples could kiss without any problem, tension or discomfort. It was good.

Shane's quotation illustrates the participants' discursive construction of LGBT sport as a space mainly occupied by gaie sexuality, thus minimizing the presence of other non-conventional genders and sexualities. We can only infer through the participants' narratives and their assumption that "everyone's gaie," that they rearticulated a discourse that was generally circulated in LGBT sport and that associated this sport space with a gaie sport space. Moreover, this quotation brings to light Shane's paradoxical construction of sexuality within her sport space. On the one hand, she tends to reproduce a discourse that minimizes the importance of sexuality, in favor of a "focus on sport." Marie also articulated this in a more direct way: "it remains a game, it stays on the field so it [the fact that I'm gaie] shouldn't cause any discomfort because... Regardless of your sexual orientation, when you're in the middle of a game, you don't care!" On the other hand, Shane's narrative offers a construction of "being out" on the sporting field that is very positive and such construction confers sexuality a significant role in sport. This latter finding can be reconciled with the fact that all the participants who competed in LGBT leagues spoke of the importance of displays of non-conventional sexuality-at least gaie sexuality - and the opportunity to live a unique and empowering experience. The following exchange with Shane is a good illustration:

Shane: It exudes happiness. It's really funny. And there are so many inside jokes in the community. You know, like my friend Marc who's so gay, so effeminate and who's wearing his little skates and you can smash him into the boards. You know, those are moments of happiness you don't get in a straight league. [Shane laughs] When you chest bump with other girls, you know, I think those are great moments you don't get to experience anywhere else. [Shane laughs] That's it. So yeah, it's really wonderful.

Barbara: Even more so than when you're with your friends in a gaile bar? 
Shane: For sure. Much more. Because sport adds something. The competition and the little confrontations during games.

In the above example, we understand the fun of witnessing the performance of genders that resist the heterosexual matrix and its standards for identity. In a complex bricolage of discursive fragments, Shane both reaffirms gender stereotypes while describing the hockey game in a way that underlines the artificial nature of gender identity. The players" "performativity" (Butler, 1997) constitutes who they are: the gay and effeminate Marc, who can barely stand on his skates and who is easily checked against the boards, and Shane, who can play physical and congratulate her female team mates by "chest bumping" with them. The irony of the gender allegory is felt in this narrative. The latter also suggests an appropriation of the usually heterosexual male hegemony in a sport such as ice hockey as well as the reiteration of the connection between non-conventional sexuality and gaie sexuality. We come to understand Shane's experience in her gaie sport space as magnified in comparison to her experience in another non-heterosexual space because of the presence of sport competition. Along with Shane, several participants constructed their team sport (whether in mainstream or gaie leagues) as a space that allowed for the intensification of their experiences. In the next section, we explore the limits of this sport space and, notably, we bring to light the connection between the gaie sport space and LGBT spaces.

\section{On the Limits of Gaie Spaces}

The participants' narratives generally reflected a discursive construction of the sport space as overlapping with "official” gaile spaces ${ }^{8}$ such as Montreal's Village or as an alternative gaie space (i.e., away from the Village). As could be expected, all participants in LGBT leagues emphasized the many connections between their sport space and "official" gaile spaces. Unexpectedly though, mainstream league participants also constructed sport in relation to official gaile spaces. Indeed, most of them constructed the Village as an extension of their sport space, in the sense that the Village was represented as the geographical location of several team activities, thus blurring the frontiers between their gaie sport space and gaile spaces. In the following example, Nathalie, a 21 year-old ice hockey player, explains how, depending on the team, her sport space did or did not intersect with gai/e spaces:

Nathalie: I'd been in Montreal for two weeks and I went out with a bunch of girls from the team as well as some other girls. The first time I went out in Montreal I went to [a popular club in the Village].

Barbara: That's a good start! [Barbara Laughs]

Nathalie: Yeah. And, you know, we partied and all that. . . I think the team was half-half the year I arrived. Half of the players were gaie, maybe not selfidentified as gaie but you know, they'd kissed girls and went out with us in the Village. In the end, we partied all year but it was really fun. . . . You know, I sort of noticed that year that there was the straight gang that had boyfriends and that quietly did their own thing and us, our little gang that went out. Obviously, 
from a team spirit point of view and all that, it kind of created a divide but, at the same time, we were playing hockey and everyone was together.

The above excerpt reveals how Nathalie constructed her sport experience in relation to gaile bars and her sport space as interconnecting with gai/e spaces. The excerpt also exposes Nathalie's representation of the Village, which is not different from that of other participants. Indeed, the Village was discursively constructed mainly as a gaile space as opposed to a space for the whole LGBT communityother non-conventional sexualities were silenced within the participants' discursive portrait of the Village. The last portion of Nathalie's statement confirms the notion that the sport space's configuration may change according to the team as non-gaie team mates seemed to shun gai/e spaces in that later year; a process that was seen to put some distance between gaie and straight players. Several participants experienced this segregation based on sexuality; however some others constructed their sport space as avoiding any segregation between players of diverse sexualities, despite regularly intersecting with gai/e spaces:

It's when I got to university that I joined a team that was really half gaie, half straight. It was really, really open. And we had a deal: one week, we'd go out to a gaile bar, and the next week to a straight bar to please the whole team. Yes, to give us the opportunity to all be together as a team. (Stéphanie, 25, ice hockey)

While sport space was primarily constructed as overlapping with gaile spaces, for a few participants it was constructed as a space where they could meet and interact with other gaie women away from the Village and gai/e bars. In Amélie's words, ice hockey constituted a way to meet "people like me." Even further, Sandra constructed her sport space as the only space-other than in the privacy of her own home-in which she was able to be out:

We just watch a game, we talk to friends and I'll just put my arm around her [her girlfriend] shoulders, I'll just give her a little signal to say "look, I'm here." You know, to say "I'm able to show it [my affection] to you, I'm happy and it feels good to be able to express it." I feel comfortable touching my girlfriend in that environment, at hockey. . . I'm honestly really happy if I can at least let go a little. I'm really happy to be part of that league. (Sandra, 26 , ice hockey)

The above statement shows the performative aspect of Sandra's sex/gender reality and the significance of her sex/gender acts within her sport space. Through various acts of (transgressive) sex/gender, Sandra constitutes herself as a subject within her sport space. In contrast to a number of studies on lesbians in sport (e.g., Cahn, 1994; Griffin, 1998; Krane, 1996; Mennesson \& Clement, 2003; Riemer, 1997; Shire, Brackenridge, \& Fuller, 2000; Veri, 1999) wherein the gendered self is taken to be prior to its acts, we understand "constituting acts" (Butler, 1997) as constituting identity. Sandra's very acts of performing sex/gender constitute who she is. Her narrative also illustrates how sex/gender acts related to non-conventional sexuality can be embodied in her sport space. It also reveals how this sport space 
is constructed through the recitation of alternative discourses about sex/gender and sexuality. Within this sport space, discourses produce the (sex/gender, sexuality) effects that they name.

Sandra was not unlike most participants, who rearticulated alternative discourses about sexuality that tend to normalize gaie sexuality and give it a legitimate status as compared to heterosexuality (see more on this in Ravel \& Rail, 2006). One of the discursive strategies to accomplish this was the silencing of other nonconventional sexualities (e.g., bisexuality, butch sexuality, sexuality not attached to a label). Another was to construct gaie sexuality as a more stereotypically feminine, less visible and, consequently, less disturbing version of a non-conventional sexuality. Such construction offered a "lighter" version of homosexuality that was discursively marked by the disassociation from lesbian sexuality. Indeed, the latter was connected to the "butch" image (i.e., more conventionally masculine) and constructed in strong opposition to the relatively new, slimmer and younger gaie "ideal." Since such "lesbian light" discourses are more and more common in mainstream Quebec society, it is not so surprising to see our participants interpellated or "hailed" by the subject positions existing within this discursive formation. In addition, conversations with the participants clearly showed how they reproduced these discourses and gradually established a "gaie hegemony" in their sport space. As van Ingen has suggested (2003), this clearly reflects the idea that space is a "site for the maintenance and reproduction of complex power relations" (p. 206). The narrative materials provide ample evidence of how bisexuality and sexualities not defined by any labels tended to be minimized or associated with gaie sexuality. The following excerpt from the conversation with Sandra illustrates this quite well:

Sandra: When I'm at hockey, since the environment is more gaie, I wouldn't feel the need to tell someone [a person who would not know that she is bisexual but only that she has a girlfriend], to specify that I could be with guys at some point, that I could date guys as often as I could date girls. But, if someone asked, obviously I'd answer. I'd say that concerning... When I'll tell my parents, I'll definitely specify that. For sure, I'll say look, "it's also possible that, one day, I'll be with a guy, it's possible that..." I'm sure I'll say that, that it's not definitive, that at the moment I'm in love but we'll see.

Barbara: So why don't you specify that you're bisexual at hockey, if nobody asks?

Sandra: Because I don't think it's important for them to know. They can see that I'm happy, that's all. At hockey, they're not judgmental, it's part of their lives, they're used to it.

By constructing sexuality in relation to being in a relationship, Sandra rearticulated an alternative discourse claiming that one falls in love "with a person, not a gender." This echoed Gabrielle's construction of sexuality, as she refused any label to describe her sexuality: "For me, the idea of attaching labels [is irrelevant]..." Such a transgressive discourse, whether within the gaile community or society, was re-appropriated by a minority of the participants. These participants positioned themselves (i.e., as "bisexual," "ambiguous" or refusing labels altogether) 
outside the heterosexual/homosexual binary and, by resisting the stable and fixed categories of sexuality, illustrated the assumptions of poststructuralist and queer theories. Sandra's narrative also revealed how space was constructed as gendered and sexualized. Her "gender acts" (Butler, 1993) and her discursive construction of sexuality were changing and visibly impacted by the dominant discourses inscribed in space, which highlights the contrasting characteristics of her sport space (i.e., gaie-friendly) and of other spaces (i.e., heteronormative). We find similarity with Stéphanie's experience when she explained how she had to pass as gaie in order to play in a league:

In fact, it's a little ambiguous [my sexuality]. I'd say that it depends on what team I'm on. It depends... Yeah, it's strange to say but... Yeah, I'm like a chameleon. With my ball hockey team, I'd say that... The fact that everyone's gaie, it's like it's a prerequisite to be gaie to be on that team. ... On my broomball team, it's completely different because I'd say that the majority of the players are, in fact, bisexual. The majority of the girls on my team have had relationships with both guys and girls; some of them are with guys at the moment but have been with girls in the past and vice versa. So, in that respect, I'd say that it resembles my experience more. (Stéphanie, 25, ball hockey and broomball)

Stéphanie's narrative allowed us to understand how these subjects constituted themselves through multiple discourses and revealed the utility of Butler's notion of "fluidity" (1990) in describing their "reality." Indeed, the quotation showed how Stéphanie constructed a changing and fragmented subjectivity as she positioned herself differently in her various teams and seemed to be strongly interpellated by subject positions associated with dominant discourses at play within her teams. Stéphanie's narrative suggested that broomball was constructed in relation to the appropriation and recitation of an alternative discourse challenging the heterosexual/homosexual binary. Florence's construction of sexuality echoed Stéphanie's, as the following reveals:

When I talk to my team mates about it, I think that I'm sort of alone on my own planet because, for them, to assert themselves and to become who they are involves saying "I'm gaie forever" and, if they've been with guys before, it was more experimenting before realizing their true choice. I'm more of a waverer, I guess [she laughs]. (Florence, 31, ice hockey)

While Florence positioned herself outside the heterosexual/homosexual binary and, through discursive recitations, constructed her sport space as gaie, she nevertheless articulated discursive fragments that carry elements of resistance to the "gaie-normativity" of that space. By offering another version of non-conventional sexuality, Florence's position as a "waverer" was clearly inscribed within an alternative discourse on sexuality that reverberates queer theorists' understanding of sexuality (Butler, 1990; de Lauretis, 1993). Not only did the participants who positioned themselves as "bisexual," "ambiguous" or who refused labels altogether constructed sexuality as fluid, but a few participants who self-identified as gaie or lesbian did as well. We found Monica's experience significant on this matter:

I really want to leave the door open. And it even annoys the hell out of me that people... It's funny, I like when people more or less say to themselves "she's a lesbian" but, at the same time, it annoys the hell out of me because they put 
me in a box that I can't get out of and, as a result, I can't be attracted to guys, which is not true. (Monica, 23, volley-ball)

Monica constructed her sexuality in a more fluid way than could be expected from her initial self-identification. By disrupting the imperative of a "one-way" desire, a few participants seemed to challenge the fixity of gaie/lesbian sexuality. For them, gaie sexuality was conceptualized as a less stable and more fluid sexuality that can also incorporate bisexuality, ambiguous sexuality or sexualities not attached to any labels. We argue that the discursive constructions of a few participants challenged the gaie hegemony of their sport space, and attested to an attempt to redefine or push the limits of gaie sport space. This reveals the double potential for resistance that can be found in such space as well as it provides some evidence for the heterogeneity of "sexual dissidents" and the complexities of the "geographies of sexuality" (Binnie \& Valentine,1999).

\section{Discussion and Conclusions}

The participants' narratives offered discursive constructions of their sport as a space of resistance to heterocentrism, heterosexism and homophobia; a space that allowed alternative discourses about sexuality to dominate. Whereas Muller (2007) has reported how heteronormativity was reinforced in WNBA spaces and only occasionally resisted by lesbian fans, we found that heteronormativity along with heterocentrism, heterosexism and homophobia were particularly challenged within the participants' sport space. This first finding seems to contradict the results of several studies that reported that mainstream sport was perceived as unwelcoming to women with a non-conventional sexuality (e.g., Eng, 2002; Fusco, 1998). We are also surprised by the fact that the participants tended to construct mainstream and categorical sport space in relatively similar terms, thus blurring the frontiers between "straight" and "gaie" sport. We also noticed how the limits of gaie sport space were blurred in that sport space often overlapped with non-sport gai/e spaces (e.g., Montreal's Village). In this respect, the participants' sport constituted a space within which sport-related activities were not the only purpose, but occupied an important place along with social encounters, friendships as well as desire and love. This result needs to be contextualized as the participants all lived and practiced sport in Montreal, a city that is recognized for its climate of openness towards difference, especially with regards to sexuality. Paradoxically, we must underline the idea that such purportedly "open" climate should have a positive influence on every social space but that participants mainly constructed other spaces such as those associated with family and work as being quite heterocentred and homophobic. Consequently, there seems to be limits to the socio-cultural explanation for our participants' discursive construction of their sport space as one of the rare social spaces where heterosexism is challenged. It may be that our participants are not that different from their European or North American counterparts and that their (mostly recreational) play level has something to do with their constructions of sport as a gaie space. Indeed, it can be argued that there are many demands on athletes competing at a higher level - a greater institutionalization of sport, dependence on (often male and/or straight) coaches, consideration of sponsors, etc. - and this may influence athletes' construction of sexuality and sport space as well as their "performance" within such space. 
The second major result of this study concerns the construction of the participants' sport space as gaie, notably by the recitation of alternative discourses that normalized gaie sexuality and positioned it as an implicit norm as compared to other non-conventional sexualities. The participants mostly characterized sport space as being "gaie" and a majority of them identified themselves as gaie (as opposed to lesbian, bisexual, butch, queer, etc.). In this sense, gaie sport space was discursively constructed in a way that tended to silence the presence (which we can only infer) of lesbian, bisexual and queer individuals as well as individuals refusing labels altogether. While their discursive constructions tended to silence other non-conventional sexualities, they also seemed to reject women displaying fewer characteristics traditionally associated with femininity. For instance, the choice of the term "gaie" expressed dissociation from the term "lesbian" that carried a more "fixed" and "butchy" connotation. While constructing their sexuality as gaie, most participants (re)produced the dominant discourse about gender that stigmatizes "masculine" femininity. In doing so, they also rearticulated discourses on gender and sexuality that are circulated in the "younger" gaie community and that tend to establish a new "norm" or "ideal" for gaie women, that is a more conventionally feminine version of lesbian sexuality (see more on this in Ravel \& Rail, 2006). Caudwell (2007) has found a butch hegemony within a particular (i.e., "out" lesbian) soccer space and has shown how this dominance is challenged by the presence of a femme-inine player. In the context of our study, the portrait tends towards the opposite with gaie players constituting the norm and the butch seen as the "abject other" (Butler, 1997). We claim that gaie sport space was therefore reinforced and secured by the double marginalization of "butchy" and-to a lesser extent- "notgaie-enough" women. This echoes the spatial exclusion of certain social identities found by van Ingen (2004) in her study of a LGBT running club in Toronto.

Whereas sport space was characterized by gaie-normativity, we were able to find elements of resistance in this space. Namely, a few participants offered more nuanced constructions of sexuality by resisting the heterosexual/homosexual binary and hegemonic categories of sexuality. Moreover, even if most participants positioned themselves in relation to gaie sexuality, their discursive constructions of sexuality often incorporated fragments of discourses challenging the "traditional" conception of sexuality and echoing queer theory (Butler, 1990; de Lauretis, 1993). We acknowledge the potential for resistance found in women's sport space but are aware of the mechanisms responsible for the spatial exclusion of certain nonconventional genders and sexualities. We argue that this space also constituted a gaie closet for those who did not position themselves as gaie but nonetheless as non-heterosexual. In this respect, we find that gaie sport space cannot be associated with queer space, as in a queer space all non-conventional sexualities (e.g., sexualities not attached to any labels) and genders (e.g., butch) would be embraced. Moreover, the resistance found within the participants' sport space seems to predominantly manifest itself in "light" strategies (e.g., open conversations, jokes) as opposed to "in your face" (i.e., queer) acts of resistance to disturb the established order. Whereas the kiss-in protest organized by lesbian fans during a WNBA game was an attempt to challenge the WNBA's "heteronormative-defined space through a competing discourse of sexuality and public action" (Muller, 2007, p. 204), in the 
Montreal participants' case, gender and sexuality acts helped destabilize normative geographies and identities, but mostly in sport space.

At a more general level, this study benefited from the combined approach of our theoretical framework that incorporated feminist poststructuralism (Weedon, 1997), queer theory (Butler, 1990; de Lauretis, 1993) and spatial ethnography (Fusco, 2005, 2006a, 2006b). First, queer theory, by destabilizing the traditional conception of sex, gender and sexuality, offered us a useful lens through which we could interpret the experiences of women with a non-conventional sexuality in sport, notably with the examination of how sexuality was constructed. Considering the wide range of non-conventional sexualities performed by the participants, it was interesting to note the destabilization of the heterosexual/homosexual binary as well as the usefulness of queer theory for understanding the experiences of many of these young sportswomen. Moreover, feminist poststructuralism allowed us to understand how subjectivity was constituted through discourses and social practices and how subjects positioned themselves along several discourses. What should be emphasized here is how the participants in our study appropriated fragments of discourses that are circulated in their sport, in the gaie community and in society. In doing so, they negotiated subject positions within multiple and often contradictory discourses. For instance, by emphasizing the lightness of being gaie, they incorporated fragments of transgressive discourses on sexuality that tend to represent the dominant discourses used to construct the gaie community as well as their sports. Resisting heteronormativity, these participants subverted the established order and also established themselves as meaningful subjects within gendered and sexualized power relations. At the same time, and thereby exposing the limits of gaie sport space in terms of resistance and subversion, these same participants recited discourses that are derogatory to butches and at times relied on dominant gender and sexuality discourses that re/produced existing power relations.

Finally, the present study answered the need for further knowledge in sociology of sport that focuses on "space" in its Lefebvrean sense (1991). It provided us with a better understanding of how multiple discourses intersect with sport, sexuality and subjectivity; how subjectivity is constituted in social space; and how "the spatial and the sexual constitute one another" (van Ingen, 2003, p. 205). On this matter, we are greatly indebted to Fusco $(2005,2006 a, 2006 b)$ and van Ingen (2003, 2004) whose research paved the way for ours. Throughout the article we attempted to highlight why sport space should be understood in its contradictory nature (Lefebvre, 1991; Soja, 1989), since it is inscribed within and constructed through dominant as well as marginal gender and sexuality discourses. In that sense, sexuality and spatiality are inextricably intertwined. Our study also allowed us to illuminate the unique nature of these participants' sport space and to note how sexuality discourses that are circulated within it seem more transgressive than the ones that are circulated in the larger society. In the end, we hope that our paper has helped to make sense of gaie sport space in Montreal and showed one methodological and theoretical path that can help us capture local gender and sexuality "realities," identify spatially constitutive discourses, and imagine the possibilities of a freer, less limited sport space. 


\section{Notes}

1. The Outgames constitute an international LGBT event competing with the Gay Games as a result of important disagreements between the host committee of the Montreal 2006 Games and the Federation of the Gay Games. Despite several differences, the Outgames share with the Gay Games the idea of bringing the LGBT community around athletic and cultural competitions in an Olympic-like event.

2. We define homophobia as an "irrational fear or intolerance of lesbians, gay men, and bisexual people," and heterosexism as "a system of dominance in which heterosexuality is privileged as the only normal and acceptable form of sexual expression" (Griffin, 1998, p. xv). We share Krane's (1996) understanding of homonegativism as "purposeful, not irrational, negative attitudes and behaviors towards nonheterosexuals" (p. 238).

3. The participants competed in ice hockey $(n=8)$, ringette $(n=3)$, soccer $(n=3)$, softball $(n=2)$, broomball $(n=2)$, ball hockey $(n=2)$, volleyball $(n=1)$ and handball $(n=1)$ at levels ranging from recreational to competitive.

4. We received positive feedback from the participants concerning the resemblance of the fictional story to their experiences.

5. Amélie and Nadia were actually out in one of their teams and closeted in the other.

6. The popular TV show "The L Word" is well known in Quebec in its original version or translated in French. Some of the participants' self-chosen pseudonyms reflect their interest in the show and their appreciation of particular characters.

7. We use the term "Francophone" here, a term accepted in Quebec and, more generally, in French Canada. This term is a pertinent alternative to the term "French," which use could have lead the reader to think that the expression "gaie" comes from France, which is not the case. Indeed, in France, the term "lesbienne" (i.e., lesbian) is usually favored.

8. While it can be argued that Montreal's Village is mainly a gai space (i.e., for gay males), participants nevertheless considered the Village as a space wherein gaie sexuality was visible. In doing so, they constructed the Village as a space they could share with other non-heterosexual subjects, since few exclusively gaie spaces exist in the Village.

\section{References}

Bell, D., \& Valentine, G. (1995). Mapping desire: Geographies of sexualities. London: Routledge.

Binnie, J., \& Valentine, G. (1999). Geographies of sexuality-A review of progress. Progress in Human Geography, 23, 175-187.

Broad, K.L. (2001). The gendered unapologetic: Queer resistance in women's sport. Sociology of Sport Journal, 18, 181-204.

Butler, J. (1990). Gender trouble: Feminism and the subversion of identity. New York: Routledge.

Butler, J. (1993). Bodies that matter: On the discursive limits of sex. New York: Routledge.

Butler, J. (1997). Excitable speech: A politics of the performative. New York: Routledge.

Cahn, S.K. (1993). From the "muscle moll" to the "butch" ballplayer: Mannishness, lesbianism and homophobia in U.S. women's sport. Feminist Studies, 19, 343-368.

Cahn, S.K. (1994). Crushes, competition, and closets: The emergence of homophobia in women's physical education. In S. Birrell \& C.L. Cole (Eds.), Women, sport and culture (pp. 327-339). Champaign, IL: Human Kinetics.

Caudwell, J. (1999). Women's football in the United Kingdom. Theorizing gender and unpacking the butch lesbian image. Journal of Sport and Social Issues, 23(4), 390402 . 
Caudwell, J. (2003). Sporting gender: Women's footballing bodies as sites/sights for the (re)articulation of sex, gender, and desire. Sociology of Sport Journal, 20, 371-386.

Caudwell, J. (2006). Femme-fatale: Re-thinking the femme-inine. In J. Caudwell (Ed.), Sport, sexualities and queer/theory (pp. 145-158). London \& New York: Routledge.

Caudwell, J. (2007). Queering the field? The complexities of sexuality within a lesbianidentified football team in England. Gender, Place and Culture, 14(2), 183-196.

Cox, B., \& Thompson, S. (2000). Multiple bodies: Sportswomen, soccer and sexuality. International Review for the Sociology of Sport, 35(1), 5-20.

Cresswell, T. (1996). In place/Out of place: Geography, ideology and transgression. Minneapolis: University of Minnesota Press.

de Lauretis, T. (1993). Sexual indifference and lesbian representation. In H. Abelove, M.A. Barale, \& D.H. Halperin (Eds.), The lesbian and gay studies reader (pp. 141-158). New York: Routledge.

Denzin, N.K. (1994). The art and politics of interpretation. In N.K. Denzin \& Y.S. Lincoln (Eds.), Handbook of qualitative research (pp. 500-515). Thousand Oaks: Sage.

Duncan, N. (1996). Body space: Destabilizing geographies of gender and sexuality. London: Routledge.

Eng, H. (2002). Sporting sex/uality: Doing sex and sexuality in Norwegian sports context. Oslo: Norwegian University of Sport and Physical Education.

Eng, H. (2006). Queer athletes and queering in sport. In J. Caudwell (Ed.), Sport, sexualities and queer/theory (pp. 49-61). London \& New York: Routledge.

Epstein, S. (1996). A queer encounter: Sociology and the study of sexuality. In S. Seidman (Ed.), Queer theory/sociology (pp. 145-167). Cambridge: Blackwell.

Fontana, A. (2002). Postmodern trends in interviewing. In J.F. Gubrium \& J.A. Holstein (Eds.), Handbook of interview research (pp. 161-175). Thousand Oaks: Sage.

Foucault, M. (1972). The archeology of knowledge. New York: Harber Torchbooks. (French original published 1969)

Foucault, M. (1973). The birth of the clinic. London: Tavistock. (French original published 1963)

Foucault, M. (1977). Discipline and punish: The birth of the prison. NewYork: Pantheon Books. (French original published 1975)

Fusco, C. (1998). Lesbians and locker rooms: The subjective experience of lesbians in sport. In G. Rail (Ed.), Sport and postmodern times (pp. 87-116). New York: State University of New York Press.

Fusco, C. (2005). Cultural landscapes of purification: Sport spaces and discourses of whiteness. Sociology of Sport Journal, 22, 283-310.

Fusco, C. (2006a). Spatializing the (im)proper subject: The geographies of abjection in sport and physical activity space. Journal of Sport and Social Issues, 30(1), 5-28.

Fusco, C. (2006b). Inscribing healthification: Governance, risk, surveillance and the subjects and spaces of fitness and health. Health and Place, 12(1), 65-78.

Gavey, N. (1989). Feminist poststructuralism and discourse analysis: Contributions to feminist psychology. Psychology of Women Quarterly, 13, 459-475.

Griffin, P. (1992). Changing the game: Homophobia, sexism, and lesbians in sport. Quest, 44(2), 251-265.

Griffin, P. (1998). Strong women, deep closets: Lesbians and homophobia in sport. Champaign, IL: Human Kinetics.

Grosz, E. (1995). Space, time and perversion. New York: Routledge.

Hekma, G. (1998). "As long as they don't make an issue of it ...”: Gay men and lesbians in organized sports in the Netherlands. Journal of Homosexuality, 35(1), 1-23.

Iannota, J.G., \& Kane, M.J. (2002). Sexual stories as resistance narratives in women's sports: Reconceptualizing identity performance. Sociology of Sport Journal, 19, 347-369.

Jansen, G.G., \& Davis, D.R. (1998). Honoring voice and visibility: Sensitive-topic research and feminist interpretive inquiry. Affilia: Journal of Women and Social Work, 13(3), 289-311. 
Jarvis, N. (2006). Ten men out: Gay sporting masculinities in softball. In J. Caudwell (Ed.), Sport, sexualities and queer/theory (pp. 62-75). London \& New York: Routledge.

Keith, M., \& Pile, S. (1993). Place and the politics of identity. New York: Routledge.

Krane, V. (1996). Lesbians in sport: Toward acknowledgment, understanding, and theory. Journal of Sport and Exercise Psychology, 18, 237-246.

Kvale, S. (1996). Interviews: An introduction to qualitative research interviewing. Thousand Oaks: Sage.

Le Blanc, R. (2002). "The first fifteen”: Understanding the conspiracy of silence of gay rugby players in Aotearoa New Zealand. Unpublished doctoral dissertation, University of Otago.

Lefebvre, H. (1991). The production of space. Oxford: Blackwell.

Lupton, D. (1992). Discourse analysis: A new methodology for understanding the ideologies of health and illness. Australian Journal of Public Health, 16, 145-150.

McDowell, L. (1999). Gender, place and identity. Minneapolis: University of Minnesota Press.

Mennesson, C., \& Clement, J.P. (2003). Homosociability and homosexuality: The case of soccer played by women. International Review for the Sociology of Sport Journal, 38(3), 311-330.

Minh-Ha, T. (1989). Woman, native, other: Writing postcoloniality and feminism. Bloomington: Indiana University Press

Muller, T.K. (2007). Liberty for all? Contested spaces of women's basketball. Gender, Place and Culture, 14(2), 197-213.

Rail, G., \& Harvey, J. (1995). Body at work: Michel Foucault and the sociology of sport. Sociology of Sport Journal, 12(2), 165-180.

Rail, G. (1998). Sport and postmodern times. New York: State University of New York Press.

Ravel, B., \& Rail, G. (2006). The lightness of being "gaie:" Discursive constructions of gender and sexuality in Quebec women's sport. International Review for the Sociology of Sport, 41(3-4), 395-412.

Riemer, B.A. (1997). Lesbian identity formation and the sport environment. Women in Sport and Physical Activity Journal, 6(2), 83-107.

Shire, J., Brackenridge, C., \& Fuller, M. (2000). Changing positions: The sexual politics of a women's field hockey team 1986-1996. Women in Sport and Physical Activity Journal, 9(1), 35-64.

Soja, E. (1989). Postmodern geographies: The reassertion of space in critical social theory. London \& New York: Verso

Sykes, H. (1998). Turning the closets inside/out: Towards a queer-feminist theory in women's physical education. Sociology of Sport Journal, 15, 154-173.

Valentine, G. (1996). Renegotiating the "heterosexual street:" Lesbian production of space. In N. Duncan (Ed.), BodySpace: Destabilizing geographies of gender and sexuality (pp. 146-155). London: Routledge.

van Ingen, C. (2003). Geographies of gender, sexuality and race: Reframing the focus on space in sport sociology. International Review for the Sociology of Sport, 38(2), 201-216.

van Ingen, C. (2004). Therapeutic landscapes and the regulated body in the Toronto Front Runners. Sociology of Sport Journal, 21, 253-269.

Veri, M.J. (1999). Homophobic discourse surrounding the female athlete. Quest, 51, 355368.

Vertinsky, P. (2004). Locating a "sense of place:" Space, place and gender in the gymnasium. In P. Vertinsky and J. Bale (Eds.), Sites of sport: Space, place, experience (pp. 8-24). London: Routledge.

Weedon, C. (1997). Feminist practice and poststructuralist theory. London: Blackwell.

Weedon, C. (1999). Feminism and the politics of difference. Malden, MA: Blackwell.

Wright, J. (1995). A feminist poststructuralist methodology for the study of gender construction in physical education: Description of a study. Journal of Teaching in Physical Education, 15(1), 1-24. 
Copyright of Sociology of Sport Journal is the property of Human Kinetics Publishers. Inc. and its content may not be copied or emailed to multiple sites or posted to a listserv without the copyright holder's express written permission. However, users may print, download, or email articles for individual use. 